\title{
General Well-Being of Students and Professionals in the Field of Performing Arts in Relation to Gender and Experience
}

\author{
Parthraj Parmar ${ }^{1 *}$
}

\section{ABSTRACT}

Well-being is the state of being happy, healthy and prosperous. Well-being or welfare is a general term for the condition of an individual or group, for example their social, economic. Psychological, spiritual or medical state: high well being means that, in some sense, the individual's or group's experience is positive while low well- being is associated with negative happenings. Well-being is equated with the experience of pleasure and the absence of pain over time. The less psychological pain an individual is experiencing the more he or she is going to expenence well-being. When someone is experiencing positive well-being they are also experiencing a few other things. It involves a sense of self-fulfilment, which is the feeling of being happy and one is doing something that fully uses your abilities and talents. The feeling of having a purpose in life and connection with others are also contributors to the idea of well-being when people feel as though they have a purpose in the world they feel like they belong. They feel like they matter and it goes back to be idea that we were created for and by a purpose. Mental Health Week in 2015 has drawn attention to a new evidence-based research study that focuses on workers in the entertainment industry. The report found that entertainment industry workers are at a higher risk of experiencing a mental health problem than the rest of the general population. Because of the lifestyle and the hours that people in the entertainment industry actually work, their ability to access mental health services suffers. There is significant difference in the general well-being among male and female students in the field of performing arts. It means that the general well-being of male students is better than that of female students in the field of performing arts. It implies that there is greater negativity, anxiety and frustration among the female students. There is greater stress, depression and competitiveness amongst them affecting their general well being.

\section{Keywords: General Well Being, Students, Gender, Experience, Professional, Performing Arts}

Well Being or welfare is a general term for the condition of an individual or group, for example their social, economic. Psychological, spiritual or medical state: high well being means that, in

\footnotetext{
${ }^{1}$ Dept. of Psychology, Shiamak Davar Institute of Performing Arts, Mumbai, India *Responding Author

(C) 2016 Parmar P; licensee IJIP. This is an Open Access Research distributed under the terms of the Creative Commons Attribution License (http://creativecommons.org/licenses/by/2.0), which permits unrestricted use, distribution, and reproduction in any Medium, provided the original work is properly cited.
} 


\section{General Well-Being of Students and Professionals in the Field of Performing Arts in Relation to Gender}

and Experience

some sense, the individual's or group's experience is positive while low well- being is associated with negative happenings. Well-being is equated with the experience of pleasure and the absence of pain over time. The less psychological pain an individual is experiencing the more he or she is going to expenence well-being. When someone is experiencing positive well-being they are also experiencing a few other things. It involves a sense of self-fulfillment, which is the feeling of being happy and one is doing something that fully uses your abilities and talents (MerriamWebster). The feeling of having a purpose in life and connection with others are also contributors to the idea of well-being when people feel as though they have a purpose in the world they feel like they belong. They feel like they matter and it goes back to be idea that we were created for and by a purpose.

There are two different types of well-being

1. Cognitive well-being

2. Affective well -being

\section{Cognitive Well-Being}

Cognitive well-being is developed through assessing one's interactions with their environment and other people. "Welfare" ultimately deals with cognitive concepts such well-being, happiness and satisfaction these relate to notions such as aspirations and needs, contentment and disappointment." People tend to assess their cognitive well- being based on the social classes that are in their community. In communities with a wide variety of social statuses. The lower class will tend to compare their lifestyle to those of higher class and assess what they do and do not have and what may lead to a higher level of well-being. Whenever someone interprets their needs and wants as to being satisfied or not, it leads to a sense of cognitive well-being,

\section{Affective Well-Being}

Affective well-being is "the cumulative experience of effects'. There are five different factors that affective being can be evaluated on: anxiety comfort, depression. Pleasure, boredenthusiastic tiredness-vigor and angry- placid". Each set of these factors are polar opposites of each other. And based on what level someone is experiencing these emotions affects one's wellbeing.

\section{How well-being is affected in the field of entertainment?}

Mental Health Week in 2015 has drawn attention to a new evidence-based research study that focuses on workers in the entertainment industry. The report found that entertainment industry workers are at a higher risk of experiencing a mental health problem than the rest of the general population (Fisher et al. 2015). Because of the lifestyle and the hours that people in the entertainment industry actually work, their ability to access mental health services suffers. Things like lack of daylight and sleep has proven to attribute to mental illness, so lifestyle 


\section{General Well-Being of Students and Professionals in the Field of Performing Arts in Relation to Gender and Experience}

definitely has an impact on people's health and wellbeing People who work in this industry usually work nights and catch up on sleep during the day, creating a vicious cycle that disallows any extra time to spend on seeking mental health assistance. Depression and anxiety remain as the most common forms of mental illness experienced both by the wider public and workers in the entertainment industry. In fact, the report found that workers in the entertainment industry experience levels of anxiety " 10 times higher" than the general population and levels of depression " 5 times higher. In addition, workers in the entertainment industry are under certain pressures in their work environment that could exacerbate psychological issues. The report claims that many key factors such as: low income levels, lack of social support and the history of mental health diagnoses contribute to the growing number of people with anxiety and depression in the entertainment industry (Fisher et al. 2015). Left undiagnosed, depression and anxiety can lead to self-harm and/ or suicidal thoughts.

The concept of well-being originated from positive psychology. Positive psychology has emerged from the problem of the West. The focus of psychology is to study the improvement in the lives of the individuals. The term well-being is mostly used for specific variety of goodness e.g. living in a good environment, being of worth for the world, being able to cope with life, enjoying life etc (as cited in Singh and Shyam, 2001) Sociologists use well-being mostly in the sense of good living conditions, ecologists and biologists in terms of 'livability' and politicians and social reformers to preconceptions of what a good living environment is like, such as a good standard of Living and social equability. Many dictionaries and now Roget's new thesaurus (1980) refers to well-being using words like happiness , full of life, vital energy, interest and prosperity as well as health.

\section{General Well-Being}

General well-being as a construct refers to the harmonious functioning of the physical as well as psychological aspects of the personality, giving satisfaction to the self and benefit to the society (Siwach, 2000) .General Well Being has been defined as encompassing people's cognitive and effective evaluations of their lives (Karatzias et al 2006). Other terms have been used, interchangeably with the general well-being term, including health (Emmons and Kings, 1988) and quality of life (Quality of Life, Wikipedia, 2010). In general well-being. Main emphasis is given to health because health is the general condition of a person in all aspects. It is a level of functional and/or metabolic efficiency of an organism, often implicitly human (http://en.wikipedia.org// wiki Health). World Health Organization (1948) defined health as "a state of complete physical, mental and social well-being and not merely health as the absence of disease or infirmity”. 


\section{HOW TO ATTAIN THE STATE OF GENERAL WELL-BEING}

General well-being is a state everyone wants to achieve to live a healthy and happy life. For attaining and then maintaining general well-being there are some techniques (Shri, 2007 Dwivedi, 2005) one must incorporate in one's life:

\section{Personal Hygiene}

One must take care of personal hygiene to attain the state of general well-being. lt includes regular brushing of the teeth, daily massage of the scalp and hair, daily oil massage of the body, regular bath, cleanliness of feet and private parts, wearing of clean and seasonal clothes and avoid keeping late hours.

\section{Well-balanced diet}

It is stated that unwholesome food is the most important cause of diseases. The importance of a proper diet in health and sickness is repeatedly stressed upon. One should follow a well balanced diet to remain healthy.

\section{Regular Physical Exercise}

Regular physical exercise aids digestion and increases capacity for work and physical strength. By exercise a person gets lightness in the body, increased incapacity to work. Firmness, tolerance of difficulties, diminution of impurity and stimulation of digestion and metabolism.

\section{Adequate Sleep}

Inadequate or poor quality of sleep leads to feelings of tiredness during the day. One should get at least seven to eight hours of sleep in a comfortable bed in order to maintain one's general well-being.

\section{Effects of Environment on Health and General well-being}

Ayurveda treats bodily health not only a as personal issue hut in relation to geographical, climatic, environmental, seasonal variations. Areas which have a proper balance of dry and moist seasons and of open spaces and forests generally contribute to good health..One should take care of one's health according to environmental conditions.

\section{Public Sanitation}

Carakasamhita lays emphasis on public sanitation for maintenance of good health. Good personal habits should be encouraged. Excesses in personal life such as drinking, smoking, gambling, womanizing, over indulgence in eating should be avoided. 


\section{Stress Management Techniques}

Everyone in this materialistic world seems to be affected by stress, tension and depression too much stress can worsen the symptoms of depression and takes its toll on one's health. Avoiding unnecessary stress is easier said than done. Positive attitude, yoga, meditation and stress management classes are some stress management techniques. By applying these techniques, one remains happy and healthy.

\section{Seek support from family, friends and attend support group meetings}

Depression, emotional disturbance and negative thinking are part and parcel of human existence and they lead to alienation and isolation. One should try to get support from family. Friends and attend support group meetings to attain the state of general well-being There are also numerous online communities and forums available.

\section{Practice Forgiveness}

One should try to forgive to oneself and others for their mistakes. We are all human and make mistakes knowingly or innocently. We need to forgive ourselves and others for their mistakes. It will enhance the feeling of well-being that helps in attaining the state of general well being.

\section{Make time for ourselves}

We sometimes feel that we have no time for ourselves either. We should try to make time for own hobbies and interests to remain happy and healthy.

The subject of this research project is: General Well- Being of Students and Professionals in the Field of Performing Arts In Relation to Gender and Experience.

This research project involves a study of the students at the Shiamak Davar Institute of Performing Arts, Mumbai.

General Well being Scale: General Well Being Scale (GWBS) is constructed and standardized by investigator and supervisor (Kalia and Deswal, 2011). The scale consists of 55 items represented in four sub-scales: physical well-being, emotional well-being, social well-being and institute well-being. It is a self-reported five-point scale including positive and negative items ranging from strongly disagree, disagree, undecided, agree, and strongly agree. 
General Well-Being of Students and Professionals in the Field of Performing Arts in Relation to Gender and Experience

Distribution of Items in the Final Version of GWBS

\begin{tabular}{|l|l|l|l|l|}
\hline Category & Subscale & Positive Items & Negative Items & Total \\
\hline A & $\begin{array}{l}\text { Physical Well- } \\
\text { Being }\end{array}$ & $1,2.3 .4,5.6,10,11$ & $7,8,9$ & 11 \\
\hline B & $\begin{array}{l}\text { Emotional Well- } \\
\text { Being }\end{array}$ & $22,23,24,25$ & $\begin{array}{l}12,13,14,15,16,17,18,19,2 \\
0,21\end{array}$ & 14 \\
\hline C & Social Well-being & $\begin{array}{l}26,27,28,29,30,31,32,33 \\
, 34,35,36,37,42\end{array}$ & $38,39,40,41$ & 17 \\
\hline D & School Well-being & $51,52,5354,55$ & $43,44,45,46,47,48,49,50$ & 13 \\
\hline Total & & & & $\mathbf{5 5}$ \\
\hline
\end{tabular}

Scoring Pattern for Positive and Negative Items

\begin{tabular}{|l|l|l|l|l|l|}
\hline Response & Strongly Disagree & Disagree & Undecided & Agree & Strongly Agree \\
\hline Positive Items & 1 & 2 & 3 & 4 & 5 \\
\hline Negative Items & 5 & 4 & 3 & 2 & 1 \\
\hline
\end{tabular}

Interpretation and Classification of Raw Scores of General Well-Being Scale

\begin{tabular}{|l|l|l|}
\hline Interpretation & Range of Scores for Males & Range of Scores for Females \\
\hline High General Well-being & $231-275$ & $226-275$ \\
\hline Average General Well- Being & $168-230$ & $177-225$ \\
\hline Low General Well- Being & Below 167 & Below 176 \\
\hline
\end{tabular}

\section{Hypothesis}

1. There is no significant level of difference in the general well-being of male and female students in the Field of Performing Arts.

2. There is no significant difference between the general well-being of professionals with more than ten years of experience and professionals with less than ten years of significance in the field of Performing Arts.

3. There is no significant difference between the physical well-being of male and female students in the field of performing arts.

4. There is no significant difference between the emotional well-being of male and female students in the field of performing arts.

5. There is no significant difference between the social well-being of male and female students in the field of performing arts.

6. There is no significant difference between the school/institute well being of male and female students in the field of performing arts.

7. There is no significant difference in the physical well-being of professionals with more than ten years of experience and professionals with less than ten years of experience in the field of performing arts.

8. There is no significant difference in the emotional well-being of professionals with more than ten years of experience and professionals with less than ten years of experience.

(C) The International Journal of Indian Psychology, ISSN 2348-5396 (e)| ISSN: 2349-3429 (p) | 60 
9. There is no significant difference between the social well-being of professionals with more than ten years of experience and professionals with less than ten years of experience

10. There is no significant difference between the school/institute well-being of professionals with more than ten years of experience and professionals with less than ten years of experience.

\section{Variables in the Study}

Variables are defined as characteristics of persons, objects, groups or events to which Qualitative and quantitative values can be assigned.

\section{Independent Variables}

1. Gender ( male and female students )

2. Institute ( Shiamak Davar Institute of Performing Arts)

3. Experience ( Professionals with more experience and professionals with less experience)

\section{Dependent Variables}

1. Scores of difference of general well- being.

2. The objective of taking these variables was to investigate the perceived impact of competition and the desire to succeed on students and young professionals in the field of performing arts.

3. These variables were measured by administering the General Well Being Scale.

\section{Sample Design}

\begin{tabular}{|c|c|c|c|}
\hline \multirow{3}{*}{ Gender } & \multicolumn{2}{|l|}{ Name of the Institute } & \multirow{3}{*}{ Total } \\
\hline & \multicolumn{2}{|c|}{ Shiamak Davar Institute of performing Arts } & \\
\hline & $\begin{array}{l}\text { Professional Experience of More } \\
\text { than } 10 \text { years }\end{array}$ & $\begin{array}{l}\text { Professional Experience of Less } \\
\text { Than } 10 \text { years }\end{array}$ & \\
\hline Male & 30 & 30 & 60 \\
\hline Female & 30 & 30 & 60 \\
\hline Total & 60 & 60 & 120 \\
\hline
\end{tabular}

1. $\quad$ Gender (Male and Female)

2. Professional Experience of More than Ten Years and Less Than 10 Years

3. $\quad$ Field (Performing Arts)

4. Institute: Shiamak Davar Institute of Performing Arts

\section{RESULT DISCUSSION}

\section{Statistical Analysis}

Table 4.3.1 showing general well-being among male and female students in the field of performing arts

(C) The International Journal of Indian Psychology, ISSN 2348-5396 (e)| ISSN: 2349-3429 (p) | 61 
General Well-Being of Students and Professionals in the Field of Performing Arts in Relation to Gender and Experience

\begin{tabular}{|l|l|l|l|l|l|l|l|}
\hline GROUP & $\mathbf{N}$ & Mean $\overline{\mathbf{X}}$ & SD & SEM & SED & 't' VALUE & Level of Significant \\
\hline Male & 30 & 206.23 & 29.62 & 5.41 & 6.843 & 3.2589 & 0.01 \\
\hline Female & 30 & 189.93 & 22.96 & 4.19 & & & \\
\hline
\end{tabular}

In Table 4.3.1 the general well-being among male and female students in the field of performing arts is shown in the value of' $t$ '.

The Mean of male students is 206.23 and that of female students is 189.93, the Standard Deviation of male and female students is 29.62 and 22.96 respectively, the value of ' $t$ ' of the general well-being of male and female students in the field of performing arts is 3.2589 which is higher than the tabulated value 2.00 at the level of significant 0.01 . Therefore the hypothesis is rejected. There is significant difference in the general well-being among male and female students in the field of performing arts. It means that the general well-being of male students is better than that of female students in the field of performing arts. It implies that there is greater negativity, anxiety and frustration among the female students. There is greater stress, depression and competitiveness amongst them affecting their general well being.

Table 4.3.2 showing general well-being of professionals with more than ten years and less than ten years experience

\begin{tabular}{|c|c|c|c|c|c|c|c|}
\hline GROUP & $\mathbf{N}$ & $\begin{array}{c}\text { Mean } \\
\overline{\mathbf{X}}\end{array}$ & SD & SEM & SED & $\begin{array}{l}\text { 't' } \\
\text { VALUE }\end{array}$ & $\begin{array}{l}\text { Level of } \\
\text { Significant }\end{array}$ \\
\hline $\begin{array}{l}\text { Professionals with more than } \\
10 \text { years of Experience }\end{array}$ & 30 & 196.67 & 33.05 & 6.03 & \multirow{2}{*}{7.943} & \multirow{2}{*}{1.4268} & \multirow{2}{*}{ N S } \\
\hline $\begin{array}{l}\text { Professionals with less than } \\
10 \text { years of experience }\end{array}$ & 30 & 185.33 & 28.29 & 5.16 & & & \\
\hline
\end{tabular}

In Table 4.3.2, the general well-being of professionals with more than ten year of experience and professionals with less than ten years of experience in the field of performing arts is shown in the value of ' $\mathrm{t}$ '.

The mean of professionals with more than ten years of experience in the field of performing arts is 196.67 and that of professionals with less than ten years of experience is 185.33. The value of ' $\mathrm{t}$ ' of the General Well-Being of professionals with more than ten years of experience and professionals with less than ten years of experience is 1.4268, which is less than the tabulated value 2.00 at no significant level. Therefore there is no significant difference between the general well-being of professionals with more than ten years of experience and professionals with less than ten years of experience in the field of performing arts. Thus the hypothesis is accepted. It means that the levels of general well-being among professionals with more than ten 
General Well-Being of Students and Professionals in the Field of Performing Arts in Relation to Gender and Experience

years of experience and professionals with less than ten years of experience in the field of performing Arts are the same.

Table 4.3.3 Showing Physical well-being among male and female students in the field of performing arts.

\begin{tabular}{|l|l|l|l|l|l|l|l|}
\hline GROUP & $\mathbf{N}$ & Mean $\overline{\mathbf{X}}$ & SD & SEM & SED & 't' VALUE & Level of Significant \\
\hline MALE & 30 & 41.23 & 8.90 & 1.63 & 2.094 & 1.3850 & N S \\
\hline FEMALE & 30 & 38.33 & 7.23 & 1.32 & & & \\
\hline
\end{tabular}

In Table 4.3.3 The physical well-being of male and female students in the field of performing arts is shown in the value of ' $t$ '.

The Mean of male students is 41.23 and that of female students 38.33, the Standard Deviation of male and female students is 8.90 and 7.23 respectively, the value of ' $t$ ' of the physical wellbeing of male and female students is 1.3850 which is less than the tabulated value of 2.00 at no significant level. Therefore there is no significant difference between the physical well-being of male and female students in the field of performing arts. Thus, the hypothesis is accepted. It means that the levels of the physical well-being of male and female students in the field of performing arts are the same

Table 4.3.4 Showing Emotional well-being among male and female students in the field of performing arts

\begin{tabular}{|l|l|l|l|l|l|l|l|}
\hline GROUP & $\mathbf{N}$ & Mean $\overline{\mathbf{X}}$ & SD & SEM & SED & 't' VALUE & Level of Significant \\
\hline MALE & 30 & 51.63 & 8.15 & 1.49 & \multirow{2}{*}{2.084} & 2.3511 & 0.05 \\
\hline FEMALE & 30 & 46.73 & 8.00 & 1.46 & & & \\
\hline
\end{tabular}

In Table 4.3.4 the emotional well-being of male and female students in the field of performing arts are shown in the value of ' $t$ '.

The Mean of male students is 51.63 and that of female students is 46.73 , the Standard Deviation is 2.084, the value of ' $t$ ' of the emotional well-being of male and female students in the field of performing arts is 2.3511 which is higher than the tabulated value of 2.00 at the level of significant of 0.05 . Therefore there is a significant difference between the emotional well-being of male and female students in the field of performing arts. Thus the hypothesis is rejected. It means that the emotional well-being of male students is better than that of female students in the field of performing arts. It implies that there is greater negativity, anxiety and frustration among the female students. There is greater stress, depression and competitiveness amongst them affecting their emotional well being. 
General Well-Being of Students and Professionals in the Field of Performing Arts in Relation to Gender and Experience

Table 4.3.5 Showing Social well-being among male and female students in the field of performing arts

\begin{tabular}{|l|l|l|l|l|l|l|l|}
\hline GROUP & N & Mean $\overline{\mathbf{X}}$ & SD & SEM & SED & 't' VALUE & Level of Significant \\
\hline MALE & 30 & 63.87 & 10.20 & 1.86 & \multirow{2}{*}{2.477} & 3.0684 & \multirow{2}{*}{0.01} \\
\hline FEMALE & 30 & 56.27 & 8.95 & 1.63 & & & \\
\hline
\end{tabular}

In Table 4.3.5., the social well-being of male and female students in the field of performing arts is shown in the value of ' $t$ '.

The Mean of male students is 63.87 and that of female students is 56.27, the Standard Deviation of male and female students in the field of performing arts is 10.20 and 8.25 respectively, the value of ' $t$ ' of the social well-being of male and female students is 3.0684 at the level of significant of 0.01 . Therefore, there is significant difference between the social well-being of male and female students in the field of performing arts. Thus, the hypothesis is rejected. The social well-being of male students in the field of performing arts is better than that of the female students. It implies that there is greater negativity, anxiety and frustration among the female students. There is greater stress, depression and competitiveness amongst them affecting their social well being.

Table 4.3.6 Showing School/Institute well-being among male and female students in the field of performing arts

\begin{tabular}{|l|l|l|l|l|l|l|l|}
\hline GROUP & $\mathbf{N}$ & Mean $\overline{\mathbf{X}}$ & SD & SEM & SED & 'T' VALUE & Level of Significant \\
\hline MALE & 30 & 49.50 & 9.05 & 1.65 & 2.173 & 2.7462 & 0.01 \\
\hline FEMALE & 30 & 43.53 & 7.72 & 1.41 & & & \\
\hline
\end{tabular}

In Table 4.3.6 the school / institute well-being of male and female students in the field of performing arts is shown in the value of ' $t$ '.

The Mean of male students is 49.50 and of female students is 43.33 , the Standard Deviation of male and female students is 9.05 and 7.72 respectively, the value of ' $t$ ' is 2.7462 which is higher than the tabulated value of 2.00 . Therefore there is a significant difference between the school/ institute well-being of male and female students in the field of performing arts. Thus, the hypothesis is rejected. It means that the school/institute well-being of male students in the field of performing arts is better than of the female students. It implies that there is greater negativity, anxiety and frustration among the female students. There is greater stress, depression and competitiveness amongst them affecting their school/institute well- being. 
General Well-Being of Students and Professionals in the Field of Performing Arts in Relation to Gender and Experience

Table 4.3.7 Showing Physical well-being of professionals with more than and less than ten years of experience

\begin{tabular}{|l|l|l|l|l|l|l|l|}
\hline GROUP & $\mathbf{N}$ & $\begin{array}{c}\text { Mean } \\
\overline{\mathbf{X}}\end{array}$ & SD & SEM & SED & 't' VALUE & $\begin{array}{l}\text { Level of } \\
\text { Significant }\end{array}$ \\
\hline $\begin{array}{l}\text { PROFESSIONALS } \\
\text { WITH MORE } \\
\begin{array}{l}\text { THAN TEN YEARS } \\
\text { OF EXPERIENCE }\end{array}\end{array}$ & 30 & 43.53 & 7.72 & 1.41 & & & \\
\hline $\begin{array}{l}\text { PROFESSIONALS } \\
\begin{array}{l}\text { WITH LESS THAN } \\
\text { TEN YEARS OF } \\
\text { EXPERIENCE }\end{array}\end{array}$ & 30 & 38.20 & 8.13 & 1.48 & 2.047 & 2.6059 & 0.01 \\
\hline
\end{tabular}

In Table-4.3.7 The physical well-being of professionals with more than ten years of experience and professionals with less than ten years of experience in the field of performing arts has been shown in the value of ' $t$ '.

The Mean of professionals with more than ten years of experience is 43.53 and that of professionals with less than ten years of experience is 38.20, the standard deviation of professionals with more than ten years of experience and professionals with less than ten years of experience is 7.72 and 8.13 respectively, the value of ' $t$ ' of the physical well-being of professionals with more than ten years of experience and professionals with less than ten years of experience is 2.6059 which is higher than the tabulated value of 2.00 at the level of significant of 0.01 . Therefore there is significant difference between the physical well-being of professionals with more than ten years of experience and professionals with less than ten years of experience. Thus the hypothesis is rejected. It means that the physical well-being of professionals with more than ten years of experience is better than that of professionals with less than ten years of experience. It implies that there is greater negativity, anxiety and frustration among professionals with less than ten years of experience. There is greater stress, depression and competitiveness amongst them affecting their physical well- being.

Table 4.3.8 Showing Emotional well-being of professionals with more than and less than ten years of experience

\begin{tabular}{|l|l|l|l|l|l|l|l|}
\hline GROUP & $\mathbf{N}$ & $\begin{array}{c}\text { Mean } \\
\overline{\mathbf{X}}\end{array}$ & SD & SEM & SED & $\begin{array}{l}\text { 't' } \\
\text { VALUE }\end{array}$ & Level of Significant \\
\hline $\begin{array}{l}\text { PROFESSIONALS } \\
\begin{array}{l}\text { WITH MORE } \\
\text { THAN TEN YEARS } \\
\text { OF EXPERIENCE }\end{array}\end{array}$ & 30 & 49.03 & 10.57 & 1.93 & & & \\
\hline $\begin{array}{l}\text { PROFESSIONALS } \\
\begin{array}{l}\text { WITH LESS THAN } \\
\text { TEN YEARS OF } \\
\text { EXPERIENCE }\end{array}\end{array}$ & 30 & 49.07 & 7.79 & 1.42 & 2.398 & 0.0134 & N S \\
\hline
\end{tabular}

(C) The International Journal of Indian Psychology, ISSN 2348-5396 (e)| ISSN: 2349-3429 (p) | 65 


\section{General Well-Being of Students and Professionals in the Field of Performing Arts in Relation to Gender}

and Experience

In table 4.3.8, the emotional well-being of professionals with more than ten years of experience and professionals with less than ten years of experience is shown in the value of ' $t$ '.

The mean of professionals with more than ten years of experience is 49.03 and that of professionals with less than ten years of experience is 49.07, the standard deviation of professionals with more than ten years of experience and professionals with less than ten years of experience is 10.57 and 7.79 respectively, the value of ' $t$ ' of the emotional well-being of professionals with more than ten years of experience and professionals with less than ten years of experience is 0.0134 which is lower than the tabulated value of 2.00 at no significant level. Therefore, there is no significant difference between the physical well-being of professionals with more than ten years of experience and professionals with less than ten years of experience. Thus, the hypothesis is accepted. It means that the levels of the physical well-being of professionals with more than ten years of experience and professionals with less than ten years of experience are the same.

Table 4.3.9 Showing Social well-being of professionals with more than and less than ten years of experience

\begin{tabular}{|l|c|c|c|c|c|l|l|}
\hline GROUP & $\mathbf{N}$ & $\begin{array}{c}\text { Mean } \\
\overline{\mathbf{X}}\end{array}$ & SD & SEM & SED & 't' VALUE & $\begin{array}{l}\text { Level of } \\
\text { Significant }\end{array}$ \\
\hline $\begin{array}{l}\text { PROFESSIONALS } \\
\text { WITH MORE THAN } \\
\text { TEN YEARS OF } \\
\text { EXPERIENCE }\end{array}$ & 30 & 62.17 & 12.69 & 2.32 & & & \\
\hline $\begin{array}{l}\text { PROFESSIONALS } \\
\text { WITH LESS THAN } \\
\begin{array}{l}\text { TEN YEARS OF } \\
\text { EXPERIENCE }\end{array}\end{array}$ & 30 & 53.47 & 12.59 & 2.30 & & & \\
\hline
\end{tabular}

In Table 4.3.9, the social well-being of professionals with more than ten years of experience and professionals with less than ten years of experience in the field of performing arts is shown in the value of ' $t$ '.

The Mean of professionals with more than ten years of experience is 62.17 and that of professionals with less than ten years of experience is 53.47, the Standard Deviation of professionals with more than ten years of experience and professionals with less than ten years of experience is 12.69 and 12.59 respectively, the value of ' $t$ ' of the social well-being of professionals with more than ten years of experience and professionals with less than ten years of experience is 2.6653, which is higher than the tabulated value of 2.00 at the level of significant of 0.01 . Therefore there is significant difference between the social well-being of professionals with more than ten years of experience and professionals with less than ten years of 
experience. Thus, the hypothesis is rejected. It means that the social well-being of professionals with more than ten years of experience is better than that of professionals with less than ten years of experience in the field of performing arts. It implies that there is greater negativity, anxiety and frustration among professionals with less than ten years of experience. There is greater stress, depression and competitiveness amongst them affecting their social well- being.

Table 4.3.10 Showing School/Institute well-being of professionals with more than and less than ten years of experience

\begin{tabular}{|l|c|c|c|c|c|l|l|}
\hline GROUP & $\mathbf{N}$ & $\begin{array}{c}\text { Mean } \\
\overline{\mathbf{X}}\end{array}$ & SD & SEM & SED & $\begin{array}{l}\text { 'T' } \\
\text { VALUE }\end{array}$ & $\begin{array}{l}\text { Level of } \\
\text { Significant }\end{array}$ \\
\hline $\begin{array}{l}\text { PROFESSIONALS } \\
\text { WITH MORE THAN } \\
\begin{array}{l}\text { TEN YEARS OF } \\
\text { EXPERIENCE }\end{array}\end{array}$ & 30 & 45.00 & 9.07 & 1.66 & & & \\
\hline $\begin{array}{l}\text { PROFESSIONALS } \\
\text { WITH LESS THAN } \\
\begin{array}{l}\text { TEN YEARS OF } \\
\text { EXPERIENCE }\end{array}\end{array}$ & 30 & 44.60 & 8.81 & 1.61 & 2.309 & 0.1733 & NS \\
\hline
\end{tabular}

In Table 4.3.10 the school/institute well-being of professionals with more than ten years of experience and professionals with less than ten years of experience is shown in the value of ' $t$ '. The Mean of professionals with more than ten years of experience is 45.00 and that of professionals with less than ten years of experience is 44.60, the Standard Deviation of professionals with more than ten years of experience and professionals with less than ten years of experience is 9.07 and 6.81 respectively, the value of ' $t$ ' of the school / institute well-being of professionals with more than ten years of experience and professionals with less than ten years of experience is 0.1733 , which is lower than the tabulated value of 2.00 at no significant level. Therefore, there is no significant difference between the school/institute well-being of professionals with more than ten years of experience and professionals with less than ten years of experience. Thus, the hypothesis is rejected. It means that the levels of the school / institute wellbeing of professionals with more than ten years of experience and professionals with less than ten years of experience are the same.

\section{CONCLUSION OF RESEARCH}

The present study was designed to investigate the General Well-Being of Students and Professionals in the Field of Performing Arts in Relation to Gender and Experience. In view of the analysis and interpretation of data and results drawn from the data, the following conclusions can be made from the present research:

1. There is a significant difference between the general well-being of male and female students in the field of performing arts. 
2. There is no significant difference between the general well-being of professionals with more than ten years of experience and professionals with less than ten years of experience in the field of performing arts

3. There is no significant difference between the physical well-being of male and female students in the field of performing arts.

4. There is a significant difference between the emotional well-being of male and female students in the field of performing arts.

5. There is a significant difference between the social well-being of male and female students in the field of performing arts.

6. There is a significant difference between the school/institute well-being of males and female students in the field of performing arts.

7. There is a significant difference between the physical well-being of professionals with an experience of more than ten years and professionals with an experience of less than ten years in the field of performing arts.

8. There is no significant difference between the emotional well-being of professionals with more than ten years of experience and professionals with an experience of less than ten years in the field of performing arts.

9. There is a significant difference between the social well-being of professionals with more than ten years of experience and professionals with less than ten years of experience in the field of performing arts.

10. There is no significant difference between the school/institute well-being of professionals with more than ten years of experience and professionals with an experience of less than ten years in the field of performing arts.

\section{Limitations of the Present Study}

1. The first limitation of the study was the sample size, although a sample of 120 respondents was collected, comprising of 30 male students, 30 female students, 30 professionals with an experience of more than ten years and 30 professionals with an experience of less than ten years in the field of performing arts.

2. Only one institute was selected for the purpose of collecting samples for study. However, the institute is one of the top-ranking institutes of performing arts in the country and is based in the city of Mumbai. The students and professionals from this institute are from different states of India and varied socio-economic backgrounds.

3. The study was limited only to the general well-being of male and female students and professionals with an experience of more than ten years and professionals with an experience of less than ten years in the field of performing arts.

4. The study was delimited on one criterion variable such as general well-being. The findings of the present study are limited to the city of Mumbai and students and 


\section{General Well-Being of Students and Professionals in the Field of Performing Arts in Relation to Gender and Experience}

professionals of Shiamak Davar Institute of performing Arts. These factors might limit the generalization of the findings.

\section{Recommendation for future research}

No research work can be considered to be the final word on any problem because it is very difficult for the researcher to touch each and every aspect of the problem. Therefore, some suggestions have been made here for future research in this field. The suggestions are as follows:

1. The present study was carried out with certain limitations. The study was confined to 60 students and 60 professionals from a reputed institute of performing arts situated in Mumbai. The samples were drawn keeping in mind the gender and experience of the students and professionals. Moreover, the study confined itself only to the measurement of the general well-being of the respondents. Therefore, the study cannot claim to be allcomprehensive. It is hereby suggested that this research study can be carried on a larger sample than the one chosen here.

2. The research study may be expanded to include more institutes of performing arts from cities other than Mumbai. Such a study would then further strengthen the generalization of the conclusions drawn.

3. It would be further considered advisable to conduct some comparative, follow-up, longitudinal and experimental studies in the field of performing arts to assess the general well-being of people of different age groups and different economic backgrounds from other fields related to performing arts and entertainment.

\section{Acknowledgments}

The author appreciates all those who participated in the study and helped to facilitate the research process.

\section{Conflict of Interests}

The author declared no conflict of interests.

\section{REFERENCES}

American Heritage Dictionary, Fourth Edition Roget's New Thesauras. Boston, MA. : Houghton Mifflin Co. ISBN-13: 978-0395825174 ISBN-10: 0395825172

Argyle, M. (1994). The Psychology of Interpersonal Behaviour. Baltimore, M.D., Penguin ASIN: B007OM5LP6

Bhinwal. N. Understanding Well being in R. Singh\& r. Shyam (Eds.) Psychology of Well Being. New Delhi : Global Publishing House. ISBN. 9788182201965

Diener, Ed (1984). "Subjective well-being". Psychological Bulletin. 95 (3): 542-575 
Giboa, Schmeidler, Itzhak, David (2001). "A cognitive model of individual well-being". Social Choice and Welfare. 18

http://www.who.int/features/factfiles/mental_health/en/

McNulty, James; Frank D. Fincham (February 2011). "Beyond Positive Psychology". American Psychologist. 67: 101-110

Routledge Handbook of the Philosophy of Well-Being https://www.routledge.com/products Tamir, Maya; Brett Ford (2012). "Should People Pursue Feelings That Feel Good or Feelings That do Good? Emotional Preferences and Well-Being". American Psychological Association. 12 (5): 1061-1070.

How to cite this article: Parmar P (2016), General Well-Being of Students and Professionals in the Field of Performing Arts in Relation to Gender and Experience, International Journal of Indian Psychology, Volume 4, Issue 1, No. 82, ISSN:2348-5396 (e), ISSN:2349-3429 (p), DIP:18.01.147/20160401, ISBN:978-1-365-59365-9 